Original Research

\title{
Interspecific Competition for Nutrients between Submerged Macrophytes (Vallisneria natans, Ceratophyllum demersum) and Filamentous Green Algae (Cladophora oligoclona) in a Co-Culture System
}

\author{
Lu Zhang', ${ }^{1,}$, Biyun Liu ${ }^{2 *}$, Fangjie Ge², Qi Liu', Yongyuan Zhang², \\ Qiaohong Zhou', Dong $\mathrm{Xu}^{2}$, Zhenbin $\mathrm{Wu}^{2}$ \\ ${ }^{1}$ School of Resource and Environmental Engineering, Wuhan University of Technology, Wuhan, PR China \\ ${ }^{2}$ State Key Laboratory of Freshwater Ecology and Biotechnology, Institute of Hydrobiology, \\ Chinese Academy of Sciences, Wuhan, PR China
}

Received: 26 January 2018

Accepted: 20 March 2018

\begin{abstract}
The excessive proliferation of filamentous green algae (FGA) has been considered to be one of the important factors that result in poor growth or even a decline in submerged macrophytes. This study aims to investigate why FGA has stronger growth advantage than that of submerged macrophytes in the co-culture system. Assimilation of nitrogen and phosphorus nutrients, kinetics, and interspecific nutrient competition model were studied to determine the dynamic changes in nutrient assimilation between submerged macrophytes and FGA in a co-culture system with ion depletion technique. The results showed that differences were observed in the assimilation of nitrogen and phosphorus by Vallisneria natans, Ceratophyllum demersum, and Cladophora oligoclona. C. oligoclona was able to assimilate and accumulate much more nitrogen than $V$. natans and $C$. demersum, with the content of nitrogen of $5.75 \%$ (dry mass). The lower value of Michaelis-Menten constant $K_{m}(0.34 \mathrm{mg} / \mathrm{L})$ of $C$. demersum indicated that $C$. demersum had a greater affinity for phosphate. The interspecific competition results confirmed that the coexistence of $V$. natans and $C$. oligoclona, and $C$. demersum and $C$. oligoclona were unstable. Moreover, $C$. demersum had a stronger competitive ability than $V$. natans, and it can be used as a pioneer species for the recovery of submerged vegetation in eutrophic lakes.
\end{abstract}

Keywords: nutrient competition, kinetics, nitrogen, phosphorus

*e-mail: liuby@ihb.ac.cn 


\section{Introduction}

Submerged macrophytes are important components of aquatic ecosystems and have a major impact on the aquatic environment [1]. Submerged macrophytes affect lake ecosystems by assimilating the nutrient content such as nitrogen and phosphorus of lakes and improving self-purification capacity of the shallow lake to maintain water clarity. Hence, the restoration of aquatic vegetation is considered as an important ecological engineering measure and is widely applied to restore eutrophic lakes [2, 3]. However, in recent years there has been a phenomenon of excessive growth of filamentous green algae (FGA) in clear lakes in which submerged macrophytes have been successfully restored [4]. FGA is a kind of green algae with filaments such as Cladophora, Spirogyra, etc. When FGA grows to a certain stage it can form an algae mat and float on the surface of water, and after the phase of declining growth, they release harmful substances and emit an unpleasant and pungent smell. The most studied FGA includes Cladophora, Spirogyra, Hydrodictyon, etc [5]. Because Cladophora can grow normally in the temperate zone or the tropical zone, no matter the original state or eutrophic coast or estuary, brackish water, or fresh water [6, 7], and it could proliferate to a large amount. Especially the Cladophora blooms in both the Laurentian Great Lakes of North America and Lake Windermere (U.K.), its biomass could rise to a disgusting level [8,9]. Moreover, excessive proliferation of Cladophora leads to environmental problems in many shallow freshwater lakes, including a serious threat to biodiversity, oxygen deficiency, and a decline in water transparency during the decomposition phase $[10,11]$. These FGA often attach to submerged macrophytes and lead to a decline or disappearance of submerged vegetation because of mechanical damage and competition for light [12]. A decline in submerged macrophyte biomass owing to Cladophora infestation in Swan Lake and Taihu Lake in China has been reported [13]. The same phenomenon also occurred in West Lake, China, where submerged vegetation was successfully recovered. The previous study also showed that Cladophora could reduce shoot density and leaf formation of eelgrass in Waquoit Bay, USA $[14,15]$.

In addition to the damage from the physical entanglement caused by FGA to submerged macrophytes, FGA also competes with submerged macrophytes for resources such as light and nutrition. However, the reason behind the competition relationship between submerged macrophytes and FGA remains limited and underexplored. Some studies have shown that competition and complex interactions for nutrition and light conditions among plants and FGA due to overlapping niches [16, 17]. Ozimek et al. [18] showed that Cladophora could inhibit the normal growth of submerged macrophyte Elodea canadensis via light competition. Under natural conditions, the nutrition competition of macrophytes often exist at the same time with light competition, but few studies have focused on the competitive relationship and characteristics of nutrition between submerged macrophytes and FGA. Tilman's resource competition theory suggests that the competition for limiting nutrients is an important factor in determining the community composition; under conditions of limited nutrient availability, the species that have the lowest requirement of resources or those that best utilize these resources are able to better survive and grow [19]. Nitrogen and phosphorus are the main nutrients affecting the growth of algae and hydrophytes in a shallow lake [20, 21]. FGA could proliferate exceedingly in the water area where submerged macrophytes exist, and they may have the need for nitrogen and phosphorus in common, thus it is important to understand whether the adverse effects of FGA on submerged macrophytes are related to nutritional competition.

In response to stress such as competition for nutrients, certain physiological and biochemical reactions occur in FGA and submerged macrophytes. Non-structural carbohydrates, including soluble sugars act as sources of rapid energy in the continued growth and survival of the plant [22]. Some plant organs store large amounts of soluble sugars to cope with changes in environmental conditions such as nutrition, light, and temperature; such conditions also lead to a change in the response of soluble sugar [23]. Thus, the stress could lead to an increase in soluble sugars.

Over-proliferation of filamentous green algae will inevitably have a negative impact on the growth of submerged macrophytes, therefore, understanding the reasons for its over-proliferation is of great significance to the restoration of submerged macrophytes. We hypothesized that FGA has a stronger competitive advantage during the competition for nutrients, such as nitrogen and phosphorus, than that of the submerged plants in the co-culture system. The present study was conducted to explore the competition for nutrients using an established submerged plant and FGA co-culture system, in which the effects of mechanical winding and shading could be avoided. Simulation studies were conducted for the kinetics of nitrogen and phosphorus uptake by plants, and a nutrient interspecific competition model was obtained to ascertain and verify the competition result under the co-culture system. The aims of the experiment were as follows: (1) determining their competitive characteristics in nutrient competition, (2) exploring the reason for the overgrowth of FGA, and (3) obtaining information for ecological restoration of eutrophic lakes.

\section{Materials and Methods}

\section{Plant Materials and Experimental Design}

All experiments were carried out in a laboratory environment that provided stable conditions. In this 
study, Vallisneria natans and Ceratophyllum demersum were chosen because they had been successfully recovered in West Lake, Hangzhou, China, and then they showed recession for FGA over-growth. And Cladophora oligoclona as a kind of advantageous FGA in the West Lake and was used as the experimental object. All plants used in this study were collected from West Lake, Hangzhou, China $\left(30^{\circ} 24^{\prime} \mathrm{N}, 120^{\circ} 13^{\prime} \mathrm{E}\right.$; total nitrogen, $\mathrm{TN}: 3.20 \mathrm{mg} / \mathrm{L}$ and total phosphorus, TP: $0.134 \mathrm{mg} / \mathrm{L}$ in water column; the measurement method is the same as that of the TN and TP of water samples in the following materials and methods section) during May 2015, and washed with deionized water several times, rinse the adsorption particles in plants and kept in MIII nutrient solution (including $0.5 \mathrm{mM} \mathrm{NaNO}_{3}$ and $0.05 \mathrm{mM} \mathrm{KH}_{2} \mathrm{PO}_{4}$ ) [24] for 15 days pre-culture. $C$. demersum stems that were $10 \mathrm{~cm}$ in length and had one intact apex and no apparent lateral branches were chosen, and $V$. natans with integrated roots and no rotten leaves that were $10 \mathrm{~cm}$ in length from the base of the stem to the top were chosen.

All devices are subjected to high temperature sterilization to build a relatively sterile environment. Cleaned and autoclaved aquariums $(19 \times 14 \times 30 \mathrm{~cm})$ were used to establish the co-culture system, in which a grid with a $74-\mu \mathrm{m}$ mesh screen of nylon was placed to divide it into two parts. By separating co-culture of plants and algae, adverse effects of shading were avoided. Correspondingly, the control group used the same aquariums without a grid. Before beginning the experiment, pre-cultured submerged macrophytes and C. oligoclona materials were washed with deionized water several times, dried with absorbent paper, and weighed. C. oligoclona and submerged macrophytes ( $5 \mathrm{~g}$, respectively) were used for the co-culture group (CC) in which submerged macrophytes were placed on one side of the co-culture aquariums (SCC), while the weighed $C$. oligoclona was placed on the other side
(FCC) (Fig. 1). Thus the competitors had equal biomass and adequate light and space. To equalize the total biomass of the culture systems in each treatment group, while $10 \mathrm{~g} C$. oligoclona or submerged macrophytes was used for the control groups (FA, SA), all submerged macrophytes were fixed in small pots $(8 \times 8 \mathrm{~cm})$ that were filled with autoclaved (at $121^{\circ} \mathrm{C}, 1.1 \mathrm{~kg} / \mathrm{cm}^{2}$ ) fine gravel (diameter of approximately $2 \mathrm{~mm}$ ), and all C. oligoclona in each system were in a free-floating state.

Co-culture group, C. oligoclona control group, submerged plant control group were set nine replicates. The total duration of the experiment was 15 days, and three replicates of each group were taken out at 5-d intervals for determining all indexes, meaning that all the plants and algae in three replicates were harvested for determining the all index. For example, six replicates remained after the first 5 days of sampling, and so there were only three replicates of the day 15 sampling.

All aquariums were filled with $7 \mathrm{~L}$ of sterilized MIII nutrient solution and were placed under the luminous intensity of $3000 \mathrm{~lx}$ and a light/dark regime of 12:12 h at $25^{\circ} \mathrm{C}$. The nutrient solution was only added once on the first day.

\section{Growth Traits, Biomass Measurements, and Determining Soluble Sugars}

The height and biomass of plants were monitored at 5-d intervals over the experimental period. The relative height growth rates $\left(\mathrm{RGR}_{\mathrm{H}}, \mathrm{cm} / \mathrm{cm} \cdot\right.$ day) were calculated according to formula (1). The relative biomass growth rates $\left(\mathrm{RGR}_{\mathrm{B}}, \mathrm{g} / \mathrm{g}\right.$.day) were calculated according to formula (2). $H_{1}$ and $H_{2}$ were measured from the base of the stem to the top and $B_{1}$ and $B_{2}$ were based on fresh weight, $\mathrm{t}$ is time in days, and the denominator is the time between the initial ( $\mathrm{t}_{1:}$ day 0 ) and measuring time points $\left(\mathrm{t}_{2}\right.$ : day 5,10 , and 15$)$.

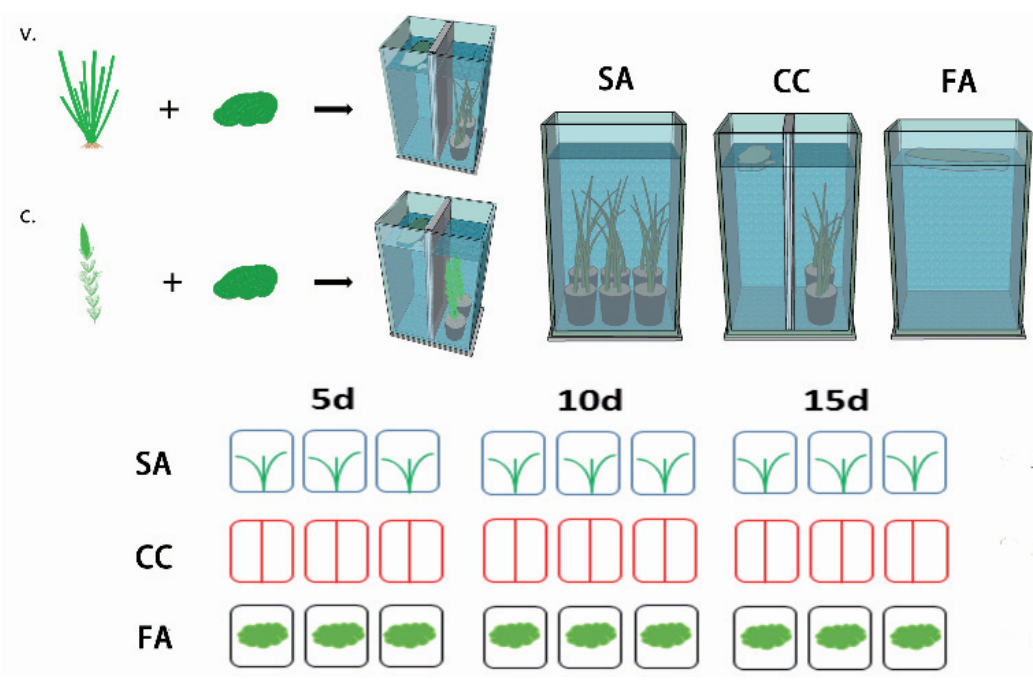

Fig. 1. Schematic device combination: V. refers to Group V. natans and C. refers to Group C. demersum; SA, submerged plant culture alone (control group); CC, co-culture; FC, C. oligoclona culture alone (control group); 5d, 10d, and 15d refer to days 5, 10 , and 15. 


$$
\begin{aligned}
R G R_{H} & =\frac{\ln H_{2}-\ln H_{1}}{t_{2}-t_{1}} \\
R G R_{B} & =\frac{\ln B_{2}-\ln B_{1}}{t_{2}-t_{1}}
\end{aligned}
$$

Triplicates of $0.2 \mathrm{~g}$ fresh weight were taken from the top branches of $C$. demersum and outside leaves of $V$. natans for determining soluble sugars at 5-d intervals using anthrone-sulfuric colorimetry according to Wang et al. [25], and the result was denoted as a percentage of fresh weight.

\section{Contents of Total Nitrogen and Phosphorus in Nutrient Solutions and Plant Samples}

The contents of total nitrogen (TN) and total phosphorus (TP) were used to represent the absorption and change of nitrogen and phosphorus content in plants and systems. TN and TP in nutrient solutions were measured every alternate day, from the first day, during the experimental period. Three replicates of $25 \mathrm{~mL}$ samples were taken and total nitrogen was determined using alkaline potassium persulfate digestion ultraviolet spectrophotometry. Ammonium molybdate spectrophotometry was used for determining total phosphorus in three $10 \mathrm{~mL}$ replicates. After sampling, the same volume of deionized water was added in order to maintain moisture and constant volume; this partial dilution has less effect on the overall concentration [26].

The contents of TN and TP in plant samples were measured at 5-d intervals. TN analysis was determined with an elemental analyzer (Vario EL cube, Elementar, Germany), and the concentrated sulfuric acid-hydrogen peroxide heating digestion method was used for digestion of dry plant samples (drying conditions: $105^{\circ} \mathrm{C}$ for $30 \mathrm{~min}$ and then drying to constant weight at $80^{\circ} \mathrm{C}$ ). Dried plant samples $(0.1 \mathrm{~g})$ were placed at the bottom of a digestive tube, $5 \mathrm{~mL}$ concentrated sulfuric acid (AR grade) was added and left overnight. On the next day, the contents were heated on a digestion furnace (KDN-08C, Xinjia, Shanghai) at about $280^{\circ} \mathrm{C}$. When the solution turned to a uniform brown-black color, 10 drops of hydrogen peroxide were added and the contents were heated until the micro-boiling point. The process was repeated several times, and each time hydrogen peroxide was added to be reduced, the color of solution must be colorless. This was heated for approximately $10 \mathrm{~min}$ to remove excess hydrogen peroxide, and was then allowed to cool. Then the digestion liquid with ammonia-free water to constant volume, placed for clarification, the supernatant of the solution was used for determining TP, and the molybdenum-antimony anti-spectrophotometric method was used to determine the content of TP (UV-1800, Shimadzu, Japan) [27]. Both contents of $\mathrm{TN}$ and TP in plant samples were represented as a percentage of dry weight.

\section{Simulation Modeling}

\section{Kinetic Equation}

In the early 1950s, Epstein used the kinetic equation of the enzymatic reaction to study the uptake of ions by plants [28], and this led to the initiation of plant nutrient kinetics. The kinetic equation of $I_{\max }$ represents the maximum assimilation rate of plants, while $K_{m}$ represents an indicator of affinity only when the product formation and enzyme liberation $\left(\mathrm{k}_{2}\right)$ is negligible in relation to the dissociation and formation rate of enzyme-substrate complex ( $\mathrm{k}_{-1}$ and $\mathrm{k}_{1}$, respectively); implying high $K_{m}$ as representing low affinity and viceversa.

The kinetics parameters were originally from the Michaelis-Menten equation. The specific calculation method is as follows: the calculated method of kinetics parameters was according to Jiang et al. [29], then used a quadratic equation $C=a+b t+c t^{2}, C$ was concentration of $\mathrm{TN}$ or $\mathrm{TP}(\mathrm{mg} / \mathrm{L})$ in nutrient solution, $\mathrm{t}$ was time (d), then got the derivative of the quadratic equation $\left(C^{\prime}=b+2 c t\right)$. And then it was calculated according to the following formula: $I_{\max }(\mu \mathrm{g} / \mathrm{g} \mathrm{FM} \cdot \mathrm{h})=|b| \times V / F W$, $K_{m}(\mathrm{mg} / \mathrm{L})=b^{2} /\left(16 a-b^{2}\right) /(4 a+c)$, in this study, $I_{\max }$ was the maximum uptake rate of nitrogen (phosphorus) ions in the experimental system; $K_{m}$ was the ion concentration in the medium when the assimilation rate is half of the maximum assimilation rate; and $V$ was volume of the culture medium.

The ion depletion technique was considered appropriate for the experimental design used in this study. It was used to evaluate the nutrient uptake rates in a long-time absorbing test, such as Li et al. [30] and Zhou et al. [31] have successfully applied this method to calculate the nutrient uptake rates of plants. This method was used to study the kinetics of nitrogen and phosphorus uptake during different treatments (submerged plant control, C. oligoclona control, and co-culture) in our study, and the nutrients were added once on the beginning of this experiment to facilitate analysis of the assimilation kinetics of nitrogen and phosphorus.

\section{Interspecific Nutrient Competition Model}

The competitive Lotka-Volterra equations are a simple explanation model used to study population dynamics of species competition for common resources. It has a wide range of applications that range from large for animals and plants to small for microbes. And it could be further extended to study nutrient interactions, such as Dunn et al. [32], who applied the Lotka-Volterra model to address aspects of competition for nutrients between seagrass and filamentous algae, and Tubay et al. [33], who analyzed how eutrophication invokes more competitions about phytoplankton in a competitive ecosystem with the Lotka-Volterra model. 
In the condition of the closed system, a new mathematical model of interspecific competition that used trophodynamics to expand the classical Lotka-Volterra competition equations was adopted in our study [34].

$$
\begin{aligned}
& \frac{d X_{1}}{d t}=\mu_{c 1} X_{1} \frac{1-\left(X_{1}+a_{12} X_{2}\right) / X_{m 1}}{1-\left(X_{1}+a_{12} X_{2}\right) / X_{m 1}^{\prime}} \\
& \frac{d X_{2}}{d t}=\mu_{c 2} X_{2} \frac{1-\left(X_{2}+a_{21} X_{1}\right) / X_{m 2}}{1-\left(X_{2}+a_{21} X_{1}\right) / X_{m 2}^{\prime}}
\end{aligned}
$$

...where $\left(X_{i}\right.$ species i population size, $\mathrm{i}=1,2$, it denoted biomass $(\mathrm{g})$ in this study; $\mu_{c i}$ - parameters related to specific rate of growth, $\mathrm{i}=1,2 ; X_{m i}$ environmental capacity, $\mathrm{i}=1,2 ; X_{m i}^{\prime}$ - nutritional parameters, $\mathrm{i}=1,2$; and $a_{i j}$ - competition parameters, $\mathrm{i}=1,2 ; \mathrm{j}=1,2$ )

A MATLAB 2014a was used to create the equations above, and then entered the biomass of submerged macrophytes and $C$. oligoclona in the co-culture system and was calculated. Finally we got the parameters $\left(X_{m l}\right.$, $\left.X_{m 2}, a_{12}, a_{21}\right)$ to describe the equal inclination diagram, and according to the shape of the equal inclination diagram to determine the results.

a)

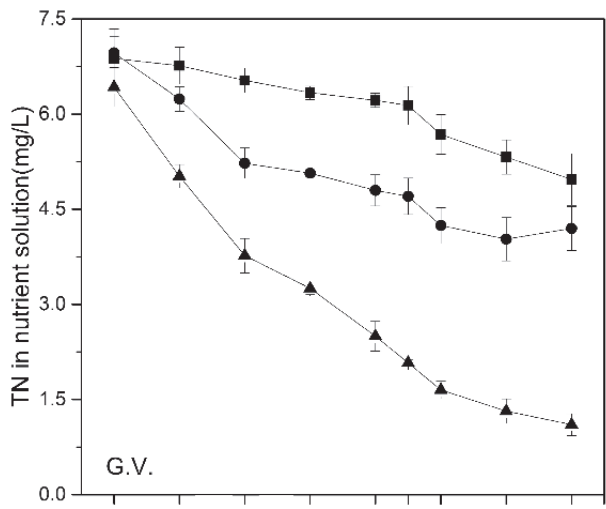

(C)

c)

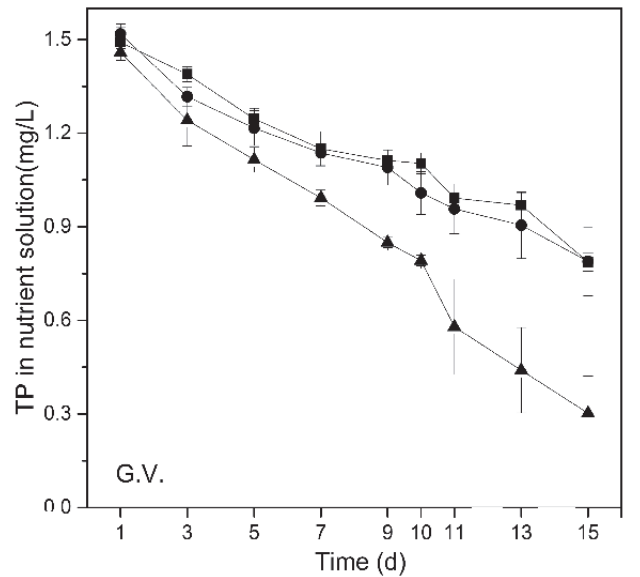

\section{Statistical Analysis}

The mean values of data and standard error were expressed as mean \pm SE and the sample number (n) was three. One-way ANOVA was performed to compare the differences in the means of the variables between treatments, Bonferroni post hoc tests were used to compare pairs of treatments, and Tukey's honest significant difference tests were performed to determine differences between means. The tests were performed using SPSS23.0 after homoscedasticity of the variance was checked; $P<0.05$ was considered to be statistically significant.

\section{Results and Discussion}

\section{Comparison of Nutrient Assimilation in Co-Culture and Control Groups}

The co-culture and control group nutrient assimilation patterns and dynamic characteristics are displayed in Fig. 4 and Table 1. The results show a decrease in TN and TP concentrations in nutrient solution. The concentrations of TN and TP in Group

b)

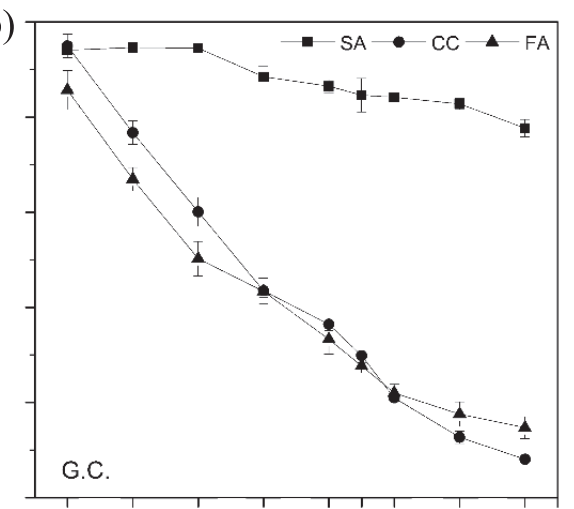

(D)

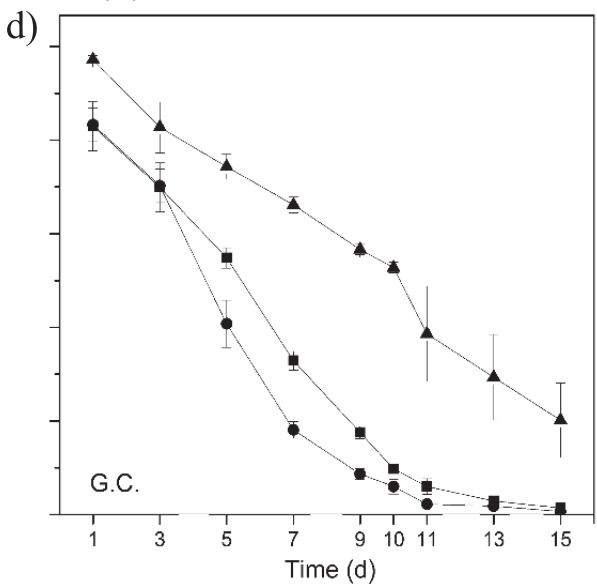

Fig. 2. Total nitrogen and total phosphorus in nutrient solution of different treatments: SA, submerged macrophytes culture alone, control group; CC, co-culture; FA, C.oligoclona culture alone, control group; Group V. natans and Group C. demersum choose to measure the index every other day form the first day (especially adding day 10 to compare with the TN/TP in plant conveniently); statistical differences on a $5 \%$ significance level, and symbols show mean values $\pm \operatorname{SE}(n=3)$ 
$V$. natans (G.V) were altered during the experiment. The trend of decline in TN and TP concentrations in C. oligoclona cultured separately (control group, FA) was the fastest, followed by co-culture (CC), and V. natans cultured separately (control group, SA) had the slowest decline trend in TN and TP. TN concentrations in SA, $\mathrm{CC}$, and FA on day 15 were $4.97 \pm 0.41,4.20 \pm 0.35$, and $1.10 \pm 0.17 \mathrm{mg} / \mathrm{L}$, respectively, while TP concentrations in SA, CC, and FA were $0.79 \pm 0.03,0.79 \pm 0.11$, and $0.30 \pm 0.12 \mathrm{mg} / \mathrm{L}$, respectively. The concentration of TN was significantly different among SA, CC, and FA $(F=32.22, P<0.001)$. TP concentrations of SA and FA, and $\mathrm{CC}$ and FA were also significantly different $(F=49.01, P<0.001)$ (Figs $2 \mathrm{a}$ and $2 \mathrm{c})$. The values obtained for the maximum uptake rates $\left(I_{\max }\right)$ of nitrogen and phosphorus for the treatments of G.V were between 3.68-18.45 and 1.55-2.41 $\mu \mathrm{g} / \mathrm{g} \mathrm{FM} \cdot \mathrm{h}$, respectively (the order was FA $>\mathrm{CC}>\mathrm{SA}$ from the highest to the lowest; Table 1), and the differences among treatments were significant in nitrogen (SA-CC, CC-FA, SA-FA) $(P<0.001, P<0.001, P<0.001)$, and the Michaelis-Menten constant $\left(K_{m}\right)$ values for nitrogen and phosphorus were between 2.48-6.13 and 0.69-0.89 $\mathrm{mg} / \mathrm{L}$, respectively (the order was $\mathrm{SA}>\mathrm{CC}>\mathrm{FA}$ from the highest to the lowest), and the differences among treatments were also significant in nitrogen (SA-CC, CC-FA, SA-FA) $(P<0.001, P<0.001, P<0.001)$.

In contrast, the decrease in TN and TP concentrations in Group C. demersum (G.C) was variable: the decline in $\mathrm{TN}$ concentrations after day 11 in $\mathrm{CC}$ was faster than that in FA, the linear variation in $\mathrm{CC}$ and $\mathrm{FA}$ was similar, and the decline in SA was the slowest $(F=163.15, P<0.001)$ (Fig. $2 b)$. TN concentrations in $\mathrm{CC}, \mathrm{FA}$, and SA on day 15 were $0.61 \pm 0.04,1.10 \pm 0.17$, and $5.83 \pm 0.14 \mathrm{mg} / \mathrm{L}$, respectively. The decline in TP concentration is shown in Fig. 2d. The decline in TP concentration was the fastest in $\mathrm{CC}$, followed by SA and, finally, the decline in FA was the slowest. The concentrations of TP in CC, SA, and FA on day 15 were $0.01 \pm 0.00,0.02 \pm 0.01$, and $0.30 \pm 0.12 \mathrm{mg} / \mathrm{L}$, respectively. From day 1 to day 3, C. demersum cultured separately showed faster assimilation of $\mathrm{P}$ than $C$. oligoclona cultured separately. However, the trend of decline in TP concentrations in $\mathrm{CC}$ was faster than that in SA and FA, CC and FA were significantly different $(F=4.16$, $P<0.05)$; hence, TP concentrations were the highest in FA. The concentrations of TP in SA and CC were close to the detection limit on day 11-15. Correspondingly, $I_{\max }$ values for nitrogen and phosphorus were between 3.04-18.45, and 2.41-4.93 $\mu \mathrm{g} / \mathrm{g} \mathrm{FM} \cdot \mathrm{h}$ in G.C (the order was $\mathrm{FA}>\mathrm{CC}>\mathrm{SA}$ for nitrogen and $\mathrm{CC}>\mathrm{SA}>\mathrm{FA}$ for phosphorus), and the differences among treatments were significant in nitrogen and phosphorus (SA-CC, CC-FA, SA-FA $) \quad(P<0.001, \quad P<0.001, \quad P<0.001) . \quad K_{m}$ values for nitrogen and phosphorus were between 1.73-6.29 and 0.34-0.69 mg/L, respectively (the order was $\mathrm{SA}>\mathrm{FA}>\mathrm{CC}$ for nitrogen and $\mathrm{FA}>\mathrm{CC}>\mathrm{SA}$ for phosphorus) (Table 1), and the differences among treatments were significant in nitrogen (SA-CC,

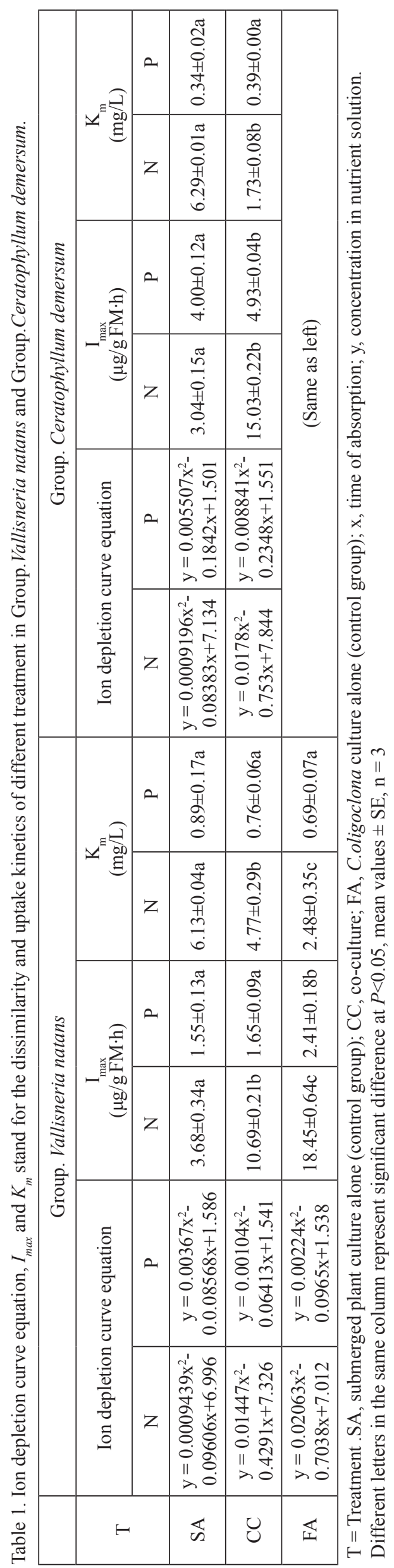


a)

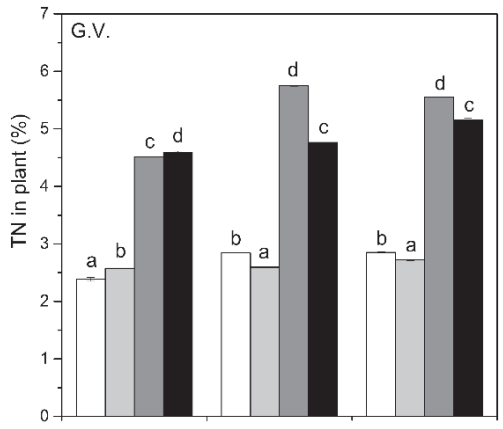

c)

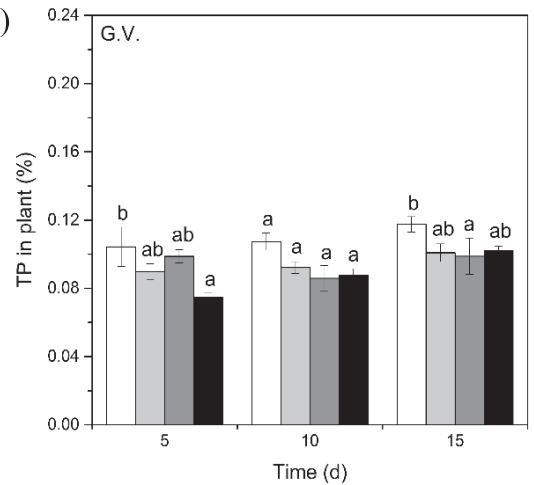

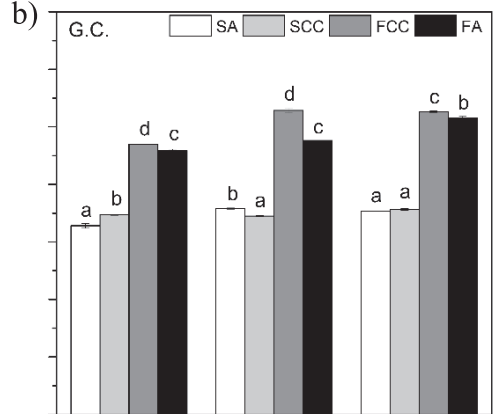

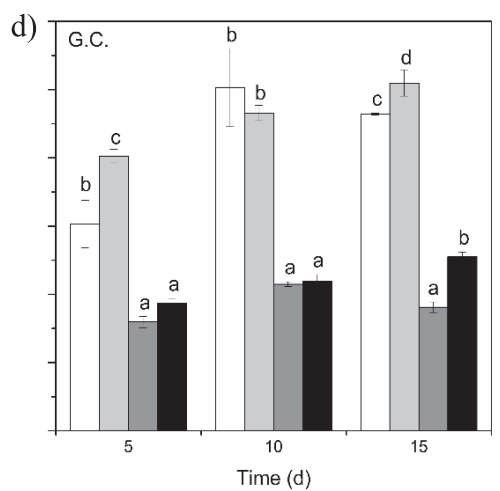

Fig. 3. Total nitrogen and total phosphorus tissue contents of Group V. natans (G.V) and Group C. demersum (G.C) at 5-d intervals - treatment: SA, submerged macrophytes culture alone (control group); SCC, submerged macrophytes in co-culture group; FCC, C.oligoclona in co-culture group; FA, C.oligoclona culture alone (control group); pairwise comparisons adopted to compare different treatments in 5,10, and $15 \mathrm{~d}$, and letters on top of columns indicate statistical differences on a 5\% significance level (Tukey-Kramer HSD); symbols show mean values \pm SE $(n=3)$

CC-FA，SA-FA) $(P<0.001, P<0.001, P<0.001)$. These results show that there were significant differences between the nutrient assimilation dynamics of the treatment groups.

We found that $C$. oligoclona had the highest $I_{\max }$ and the lowest $K_{m}$ (Table 1) by culture alone, owing to the Michaelis-Menten constant $K_{m}$ reflecting the carrier affinity for ions, and the smaller the value, the greater the affinity [35]. Thus, it indicated that C. oligoclona had a greater affinity for nitrogen than the submerged macrophytes that were tested. For G.V and G.C, TN content in C. oligoclona in the co-culture group (FCC) was higher than the independent culture of $C$. oligoclona (FA) on days 10 and 15, and a significant difference was observed on days 5, 10, and $15(F=498.50$, $P<0.001 ; F=424.16, P<0.001 ; F=387.91, P<0.001)$. Significant differences were also observed between B1 and B2 $(P<0.001, P<0.001)$ (Fig. 3a, b). The submerged macrophytes control group (SA) and co-culture group (SCC) in G.V and G.C had lower TN than C. oligoclona, and no differences were observed between SA and SCC. The sum of TN content in submerged macrophytes and C. oligoclona in co-culture treatment never exceeded the double of TN in C. oligoclona from the control treatment. The TN content in tissue of $C$. oligoclona could be up to $5.75 \%$ in co-culture, which was more than that observed for both $V$. natans $(2.85 \%)$ and $C$. demersum (3.58\%). Similar observations have been made in other studies, whereby it has been shown that Cladophora possesses higher tissue nitrogen concentrations compared to some macrophytes [36, 37]. These diferences might be related to the physiological structure and nutrient composition of the algae [38]. Because larger cell volumes allow Cladophora to store a variety of resources, and when the surrounding environment is lacking for nutrient a long time, the algae can continue to grow [39]. So the C. oligoclona could grow normally in the case of nutrient-limit concentration in the later phase of the experiment. The fastest and most assimilation of nitrogen was observed in the $C$. oligoclona control group, followed by co-culture, while the control groups of $V$. natans and $C$. demersum had the lowest assimilation because of lower $I_{\max }$ and higher $K_{m}$. However, the slower assimilation of nutrients by hydrophyte may be a growth strategy to deal with ephemeral macroalgae, and accumulate greater nutrient reserves under certain environmental conditions [40].

The changes of TP were different from TN in plant samples. For G.V, C. oligoclona in co-culture was not different during day 1 to day 10 of the assimilation process, and the percentage of TP in FCC $(0.09 \%)$ was lower than that in FA $(0.10 \%)$ on day $15(P<0.01)$. A difference was not observed between SCC and FCC (Fig. 3c). The highest TP tissue content ( $0.20 \%)$ appeared in $C$. demersum of the co-culture group on day 15. The histogram of G.C. showed that the phosphorus content was the lowest in FA. The distribution of TP can be shown by the formula $2 \mathrm{FA}<\mathrm{SCC}+\mathrm{FCC}<2 \mathrm{SA}$ 

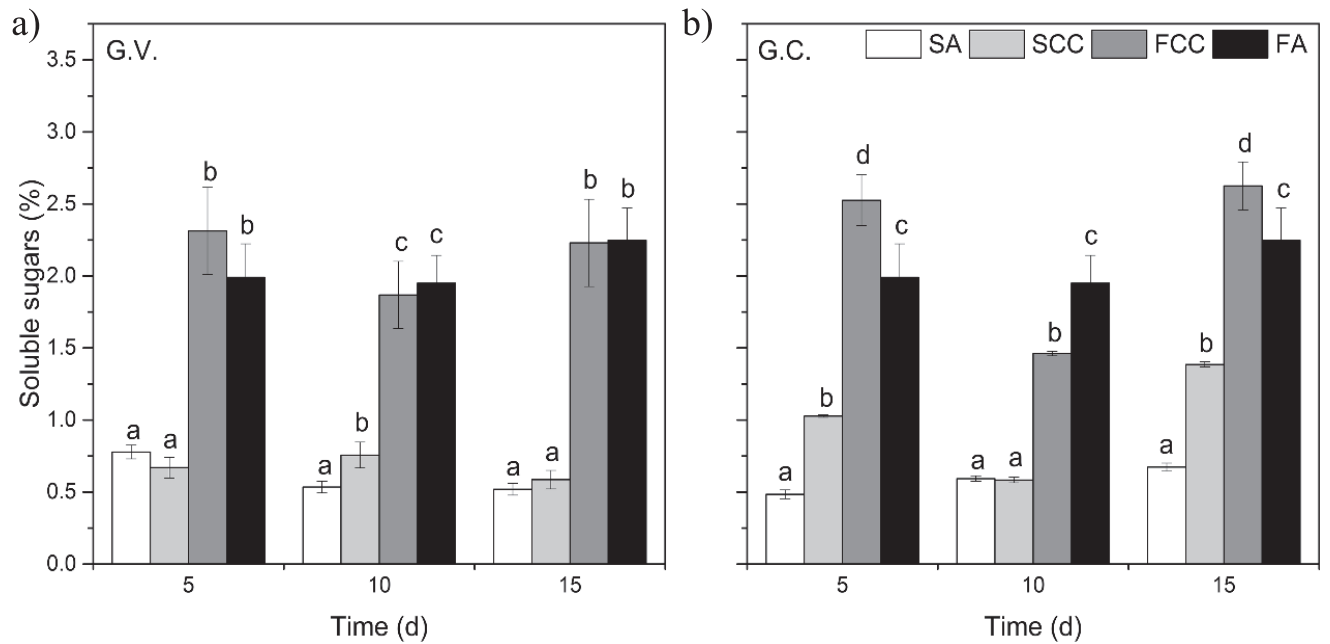

Fig. 4. Soluble sugars in Group V. natans (G.V) and Group C. demersum (G.C) at 5-d intervals. Treatment: SA, submerged macrophytes culture alone (control group); SCC, submerged macrophytes in co-culture group; FCC, C. oligoclona in co-culture group; FA, C. oligoclona culture alone (control group). Pairwise comparisons adopted to compare different treatments in 5, 10, and 15 d. Letters on top of columns indicate statistical differences on a 5\% significance level (Tukey-Kramer HSD). Symbols show mean values $\pm \operatorname{SE}(n=3)$.

(e.g., day $15,2 * 0.10<0.20+0.07<2 * 0.19$ ), and pairwise comparisons showed that there were significant differences $(P<0.01)$, except between FCC and FA on day 5, and SA-SCC and FCC-FA on day 10 (Fig. 3d).

In this study, under the condition of the biomass of the co-culture group was equal to that of the control group, the TP tissue content of $C$. demersum in coculture group was also slightly higher than the control group, suggesting that $C$. demersum and $C$. oligoclona in the co-culture groups showed a tendency to compete for promoting absorption. $V$. natans had lower assimilation and accumulation of phosphorus than C. oligoclona, and the co-culture group did not show a tendency to promote assimilation in the group $V$. natans, which might be explained by the fact that $V$. natans was not very sensitive to the presence of the $C$. oligoclona in nutrientrich conditions in the early phase of the experiment. C. demersum had higher absorption of phosphorus than C. oligoclona because of greater affinity for phosphorus, a previous study also showed that $C$. demersum exhibited an affinity for phosphorus [41]. C. demersum was shown to have tolerance to high phosphorus concentration [42], therefore $C$. demersum could also express a stronger assimilation of phosphorus even in the higher nutrient environment, and some studies have manifested that C. demersum plays an important role in maintaining low concentrations of phosphorus in water and helps to maintain clarity [43]. In addition, $C$. demersum can affect the utilization of phosphorus by algae through the competition of nutrients [44].

\section{Analysis of Nutrient Assimilation Ability by Different Species in Co-Culture Groups}

Comparisons were made between $V$. natans and $C$. demersum, with $C$. demersum seeming to be more adaptive to the competitive environment. However, different aquatic macrophyte species have different capacities of nutrient acquisition from the aquatic environment [45]. The capacity for nutrient storage depends on the rapid increase in nutritional requirements and the ability to accumulate nutrients [46]. From the morphological point of view, the leaf morphology of submerged macrophytes could be the reason why we saw a difference between $C$. demersum and $V$. natans [47], and the fine needle-like leaves of $C$. demersum form a larger specific surface area than that of $V$. natans. Furthermore, better competitiveness of $C$. demersum under conditions of limited nutrient availability can be attributed to the change in the concentration of soluble sugars. As it showed in Fig. 3, although the contents of soluble sugars for each treatment in G.V were similar at every 5-d interval, a significant difference was observed between $V$. natans and C. oligoclona in both control group and co-culture group (pairwise comparison: SA-SCC, SCC-FCC, SA-FA) $(F=172.23, P<0.001)$ on day 10 , and there were significant differences in pairwise comparison of SCC-FCC and SA-FA on day $15(F=148.79, P<0.001)$. The contents of soluble sugars were significantly higher in $C$. oligoclona $(\mathrm{FCC}, \mathrm{FA})$ than in $V$. natans $(P<0.01)$ (Fig. 4a). In contrast, the contents of soluble sugars in SCC, FCC, and FA of G.C on days 5 and 15 were higher than those on day 10 , and the content on day 15 was higher than that on day 5 (SCC: average $1.39 \pm 0.02 \%$ on day 15, FCC: average $2.63 \pm 0.17 \%$ on day 15 , FA: average $2.25 \pm 0.22 \%$ on day $15 ; F=343.15$, $P<0.001)$ (Fig. 4b) from the amount of soluble sugar accumulation. In addition, pairwise comparisons revealed that differences between $\mathrm{SA}$ and $\mathrm{SCC}$, and SA and FA on day $5(P=0.016<0.05, P<0.01)$, differences between SA and FA on day $10(P \leq 0.001)$, 

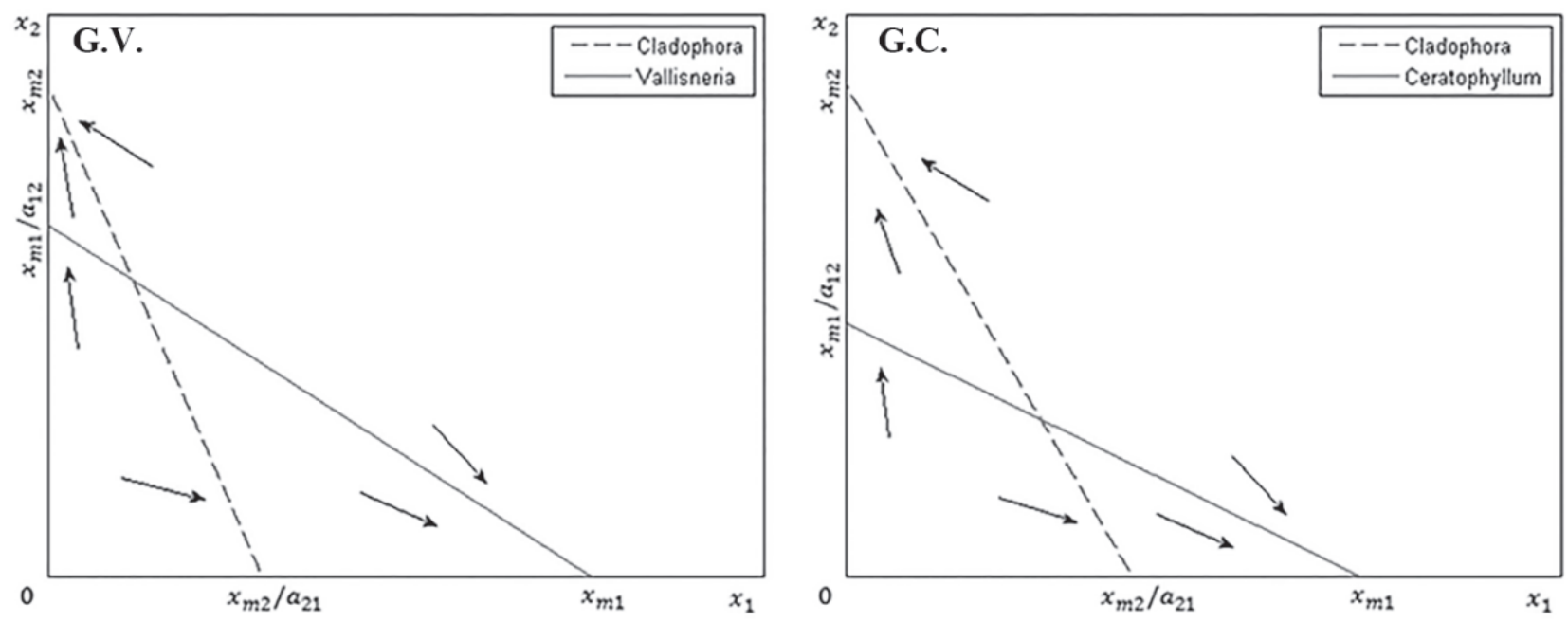

Fig. 5. Phase plane diagram of unstable coexistence (two competitive species with different nutrition requirement in a closed system). $X_{1}$ refers to species 1 , namely submerged plant; $X_{2}$ refers to species 2, namely $C$. oligoclona; competition parameters $X_{m l}$ and $X_{m 2}$, environmental capacity; and $\mathrm{a}_{12}$ and $\mathrm{a}_{21}$ represent the competition coefficient of the two species; arrows represent the trend.

and differences between SA and SCC, and SA and FA on day 15 were significant $(P<0.001)$, while pairs SA-FCC and FA-SCC were not included in the pairwise comparisons.

In our study we did not find the direct relationship between soluble sugars content and phosphorus assimilation. But soluble sugars play an important role in nitrogen metabolism, as the uptake and reduction of nitrogen in primary nitrogen metabolism all require energy supply [48], and the soluble sugars of $C$. demersum in the co-culture group exhibited a more obvious accumulation trend than $V$. natans in co-culture to deal with the lack of nutrition toward the latter phase of the experiment. However, all treatments and control of C. oligoclona showed a higher sugar content than the submerged plant, which represents the ability of C. oligoclona to store and use more energy to overcome small reductions in nitrogen concentrations in water, and the results of our research on the high nitrogen uptake of $C$. oligoclona algae also proved this point.

\section{Simulation Analysis of Competitive Results in Co-Culture Groups}

The results of the interspecific nutrient competition simulation for the co-culture group in G.V and G.C were determined by the equal inclination diagram of the $\mathrm{LV}$ model (Fig. 5). When $\mathrm{a}_{21}<X_{m 2} / X_{m 1}$, and $\mathrm{a}_{12}<X_{m 1} / X_{m 2}$, each one intersected wotj the two species equilibrium curves in the two groups, which are equilibrium points, but this equilibrium point has trended to move up or down, indicating that they were all in a state of unstable coexistence, and either of the two species could succeed. When the equilibrium point moved up to point $X_{m 2}$, it meant that species 2 (C. oligoclona) would win the competition, and when the point moved down to point $X_{m}$, species 1 (submerged plant) would win.
During the experimental period, the plants and C. oligoclona showed growth on plant height and biomass (as observed until the final day), and this phenomenon was consistent with the simulation results. The $R_{G R}$ and $R_{H} R_{B}$ data indicated that there were no differences between the values of $R_{G R}$ of submerged macrophytes belonging to G.V. and G.C., but a significant difference was observed on day 10 between submerged macrophytes cultured separately (SA) and submerged macrophytes in the co-culture group (SCC) $(F=25.79, P<0.05)$ (Fig. 6a). On day 10 , the average values of $\mathrm{RGR}_{\mathrm{H}}$ for the control and co-culture group of G.V were $0.0132 \pm 0.0043$ $\mathrm{cm} / \mathrm{cm} \cdot \mathrm{day}$ and $0.0109 \pm 0.0029 \mathrm{~cm} / \mathrm{cm} \cdot$ day, respectively. By contrast, the numbers were $0.0166 \pm 0.0002$ $\mathrm{cm} / \mathrm{cm} \cdot$ day and $0.0218 \pm 0.0011 \mathrm{~cm} / \mathrm{cm} \cdot$ day for the control and co-culture group of G.C. Moreover, for G.C. the values of $\mathrm{RGR}_{\mathrm{B}}$ in the co-culture group were higher than that in control, particularly $C$. demersum in the co-culture group had a higher rate of biomass accumulation (average $0.0323 \pm 0.0002 \mathrm{~g} / \mathrm{g} \cdot \mathrm{day}$ on day 15) (Fig. 6c), while values of $\mathrm{RGR}_{\mathrm{B}}$ of $C$. oligoclona in the co-culture group of G.V. increased in chronological order (average $0.0047 \pm 0.0001 \mathrm{~g} / \mathrm{g} \cdot \mathrm{day}$ on day 5, $0.0088 \pm 0.0010 \mathrm{~g} / \mathrm{g} \cdot$ day on day $10,0.0104 \pm 0.0009 \mathrm{~g} / \mathrm{g} \cdot$ day on day 15) (Fig. 6b). These observations suggested that they grew in an environment of constant availability of nutrition. $\mathrm{RGR}_{\mathrm{H}}$ data of $V$. natans leaves indicated an increase in growth rate even in the co-culture group. This was because of the optimal distribution of resources for the leaves to receive more sunlight and absorb more nutrients in order to achieve rapid growth [49]. On one hand, the result of coexistence demonstrates that $C$. oligoclona in equal biomass did not have much effect on the growth of $V$. natans and $C$. demersum. A previous study has indicated that FGA had no effect on the growth of submerged macrophytes at either high or 
a)
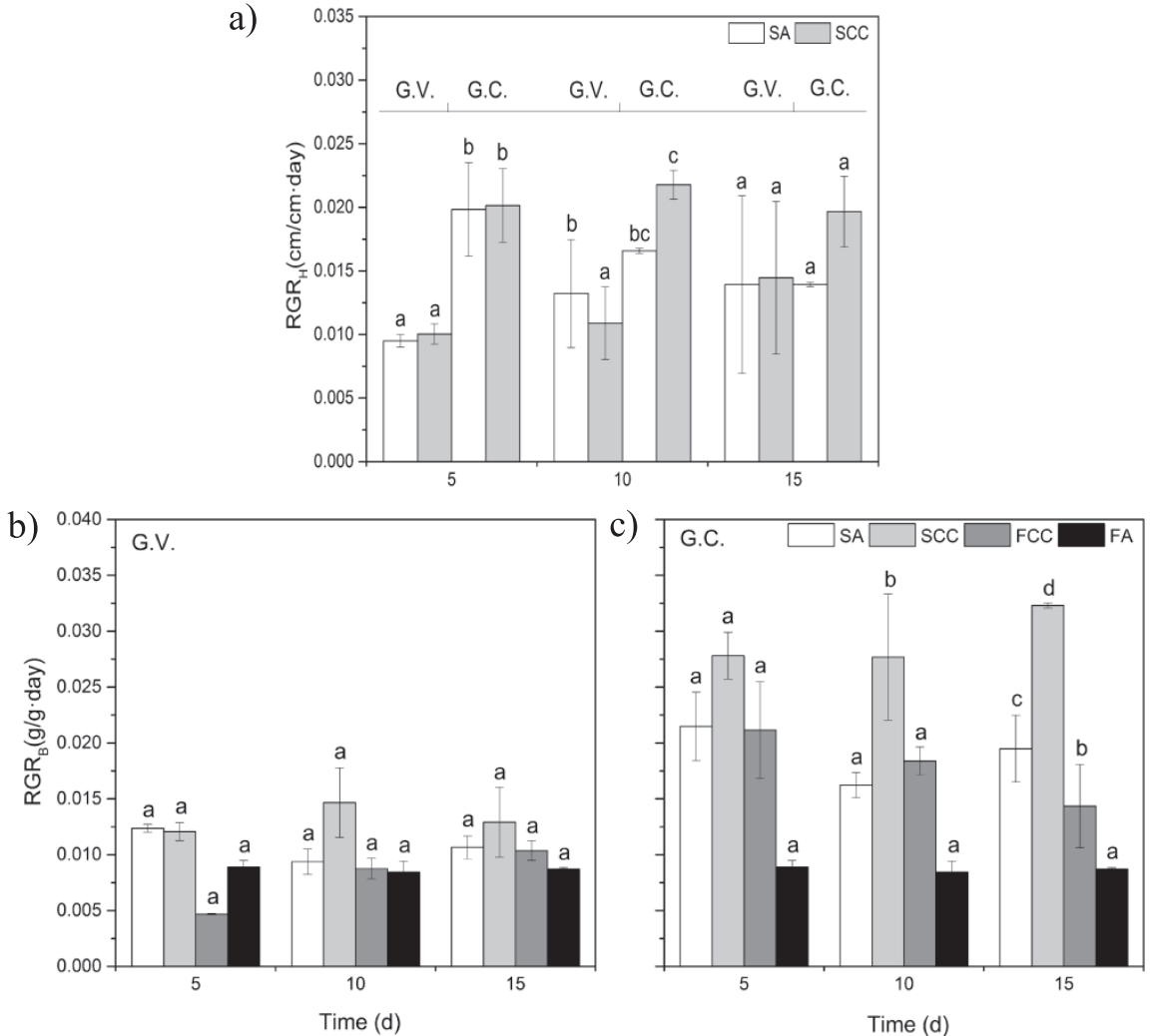

Fig. 6. Relative height growth rate $\left(\mathrm{RGR}_{\mathrm{H}}\right)$ of Group V. natans (G.V) and Group C. demersum (G.C) at 5-d intervals. Relative growth rates $\left(\mathrm{RGR}_{\mathrm{B}}\right)$ of G.V and G.C for every 5d. Treatment: SA, submerged macrophytes culture alone (control group); SCC, submerged macrophytes in co-culture group; FCC, C. oligoclona in co-culture group; FA, C. oligoclona culture alone (control group). Pairwise comparisons adopted to compare different treatments in 5, 10, and 15d. Letters on top of columns indicate statistical differences on a $5 \%$ significance level (Tukey-Kramer HSD). Symbols show mean values \pm SE $(n=3)$.

low biomass of FGA [50]. FGA has a wider ecological amplitude and can tolerate a higher concentration of nutrients than hydrophytes, and it is able to survive in the eutrophic environment [51]. Ttherefore, it has the ability to compete with submerged macrophytes. That was an explanation about natural coexistence that could happen in most cases. On the other hand, the reason for the instability of coexistence is that the nutritional requirements of the two species are different. In the environment where the nutrition of the coexisting system is constantly depleted, the winning parties of both species depend on the species that conserves power and reduces nutrient consumption to sustain growth.

\section{Conclusion}

In conclusion, submerged macrophytes and FGA have their own nutrient absorption characteristics in the co-culture system. C. oligoclona was a stronger competitor for higher nutrient assimilation ability, which may be one of the reasons for its rapid and excessive growth in the case of adequate nutrition. $C$. demersum had a high capacity for phosphorus assimilation, and could be used as a pioneer species in the recovery of submerged vegetation in eutrophic lakes. In the presence of equal biomass $C$. oligoclona, the nutrient uptake of submerged macrophytes will be affected to a certain extent from nutrient competition, but it will not affect the growth of submerged macrophytes. Thus, further studies are required to pay attention to the competitive ability of submerged macrophytes during the process of restoration of the lake ecosystem.

\section{Acknowledgements}

This study was supported by the Major Science and Technology Program for Water Pollution Control and Treatment of China 12th Five-Year Plan (grant No. 2012ZX07101007-005), and the State Key Laboratory of Freshwater Ecology and Biotechnology (grant Nos. 2016FBZ13 and 2017FB05). We appreciate the assistance of Kelang Yi, Ming Yang, and Fenli Min in the identification of algal and plant collections.

\section{Conflict of Interest}

The authors declare no conflict of interest. 


\section{References}

1. STEFANIDIS K., PAPASTERGIADOU E. Influence of hydrophyte abundance on the spatial distribution of zooplankton in selected lakes in Greece. Hydrobiologia. 656 (1), 55, 2010.

2. HERNÁNDEZ-CRESPO C., OLIVER N., BIXQUERT J., GARGALLO S., MARTÍN M. Comparison of three plants in a surface flow constructed wetland treating eutrophic water in a Mediterranean climate. Hydrobiologia. 774 (1), 183, 2016.

3. JI G., XU Z.X., WANG L.Q. Effects of floating-leaved macrophytes on water quality and phytoplankton: an in situ experiment in a Chinese shallow lake. Desalination and Water Treatment, 57 (57), 27519, 2016.

4. BAKKER E.S, VAN DONK E., DECLERCK, S.A.J., HELMSING N.R., HIDDING B., NOLET B.A. Effect of macrophyte community composition and nutrient enrichment on plant biomass and algal blooms. Basic and Applied Ecology. 11, 432, 2010.

5. PIKOSZ M., MESSYASZ B. Composition and seasonal changes in filamentous algae in floating mats. Oceanological and Hydrobiological Studies. 44 (2), 273, 2015.

6. LEE Y.C., CHANG S.P. The biosorption of heavy metals from aqueous solution by Spirogyra and Cladophora filamentous macroalgae. Bioresource technology. 102 (9), 5297, 2011.

7. POCHON X., ATALAH J., WOOD S.A., HOPKINS G.A., WATTS A., BOEDEKER C. Cladophora ruchingeri (C. Agardh) Kützing, 1845 (Cladophorales, Chlorophyta): a new biofouling pest of green-lipped mussel Perna canaliculus (Gmelin, 1791) farms in New Zealand. Aquatic Invasions. 10 (2), 123, 2015.

8. BROOKS C., GRIMM A., SHUCHMAN R., SAYERS M., JESSEE N. A satellite-based multi-temporal assessment of the extent of nuisance Cladophora and related submerged aquatic vegetation for the Laurentian Great Lakes. Remote Sensing of Environment. 157, 58, 2015.

9. HIGGINS S.N., HECKY R.E., GUILDFORD S.J. The collapse of benthic macroalgal blooms in response to selfshading. Freshwater Biology. 53, 2557, 2008.

10. GUBELIT Y.L., BEREZINA N.A. The causes and consequences of algal blooms: the Cladophora glomerata bloom and the Neva estuary (eastern Baltic Sea). Marine Pollution Bulletin. 61, 193, 2010.

11. YE N.H., ZHANG X.W., MAO Y. Z., LIANG C.W., XU D., ZOU J., ZHUANG Z.M., WANG Q.Y. 'Green tides' are overwhelming the coastline of our blue planet: taking the world's largest example. Ecological Research. 26, 477, 2011.

12. RODRIGO M.A., ROJO C., ALONSO-GUILLÉN J.L., VERA P. Restoration of two small Mediterranean lagoons: the dynamics of submerged macrophytes and factors that affect the success of revegetation. Ecological engineering. 54, 1, 2013.

13. GAO L., ZHANG L., HOU J., WEI Q., FU F., SHAO H. Decomposition of macroalgal blooms influences phosphorus release from the sediments and implications for coastal restoration in Swan Lake, Shandong, China. Ecological engineering. 60, 19, 2013.

14. HAUXWELL J., CEBRIÁN J., FURLONG C., VALIELA I. Macroalgal canopies contribute to eelgrass (Zostera marina) decline in temperate estuarine ecosystems. Ecology. 82 (4), 1007, 2001.
15. SCHMIDT A.L., WYSMYK J.K., CRAIG S.E., LOTZE, H.K. Regional-scale effects of eutrophication on ecosystem structure and services of seagrass beds. Limnology and Oceanography. 57 (5), 1389, 2012.

16. KORS A., VILBASTE S., KAIRO K., PALL P., PIIRSOO K., TRUU J., VIIK M. Temporal changes in the composition of macrophyte communities and environmental factors governing the distribution of aquatic plants in an unregulated lowland river (Emajõgi, Estonia). Boreal Environment Research. 17 (6), 460, 2012.

17. MOSS B., JEPPESEN E., SØNDERGAARD M., LAURIDSEN T.L., LIU Z. Nitrogen, macrophytes, shallow lakes and nutrient limitation: resolution of a current controversy? Hydrobiologia. 710, 3, 2013.

18. OZIMEK T., PIECZYŃSKA E., HANKIEWICZ A. Effects of filamentous algae on submerged macrophyte growth: a laboratory experiment. Aquatic Botany. 41 (4), 309, 1991.

19. TILMAN D. Resource competition between plankton algae: an experimental and theoretical approach. Ecology. $\mathbf{5 8}, 338,1977$.

20. LI Y., WANG Y., TANG C., ANIM D.O., NI L., YU Z., ACHARYA K. Measurements of Erosion Rate of Undisturbed Sediment under Different Hydrodynamic Conditions in Lake Taihu, China. Polish Journal of Environmental Studies. 23 (4), 1235, 2014.

21. YU Q., WANG H.Z., LI Y., SHAO J.C., LIANG X.M., JEPPESEN E., WANG H.J. Effects of high nitrogen concentrations on the growth of submersed macrophytes at moderate phosphorus concentrations. Water research. 83, 385, 2015.

22. JENSEN K.B., HARRISON P., CHATTERTON N.J., BUSHMAN B.S., CREECH J.E. Seasonal trends in nonstructural carbohydrates in cool-and warm-season grasses. Crop Science. 54 (5), 2328, 2014.

23. XIE D., ZHOU H., JI H., CHEN Y., AN S. Effects of buoyancy and season on turion dispersal of submerged macrophyte Potamogeton crispus L. CLEAN-Soil, Air, Water. 43, 324, 2015.

24. NICKLISCH A. The interaction of irradiance and temperature on the growth rate of Limnothrix redekei and its mathematical description. Archiv für Hydrobiologie. Supplementband. Untersuchungen des Elbe-Aestuars. 91, $1,1992$.

25. WANG X.K. Principles and techniques of plant physiological biochemical experiment (2nd Edition), Higher Education Press.pp.202-207, 2006. (in Chinese).

26. Ministry of Environmental Protection of the PRC. Determination methods for examination of water and wastewater. Beijing: China Environmental Science Press, pp. 243, 2002 [Iin Chinese].

27. WEN L., HUA C.L., PING Z.Y., XIANG L.Z. Removal of Total Phosphorus from Septic Tank Effluent by the Hybrid Constructed Wetland System. Procedia Environmental Sciences. 10, 2102, 2011.

28. EPSTEIN E., HAGEN C.E. A Kinetic study of the absorption of alkali cations by barley roots. Plant Physiology. 27, 457, 1952.

29. JIANG T.H., ZHENG S.J., SHI J.H., HU A.T., SHI R.H., XU M. Several considerations in kinetic research on nutrients uptake by plants. Plant nutrition and fertilizer sciences. 1, 11, 1995 [Iin Chinese].

30. LI J., YANG X., WANG Z., SHAN Y., ZHENG Z. Comparison of four aquatic plant treatment systems for nutrient removal from eutrophied water. Bioresource technology. 179, 1, 2015. 
31. ZHOU X., WANG G., YANG F. Characteristics of growth, nutrient uptake, purification effect of Ipomoea aquatica, Lolium multiflorum, and Sorghum sudanense grown under different nitrogen levels. Desalination. 273 (2), 366, 2011.

32. DUNN J., MCARTHUR L., SCHREIDER S. Plant biomass and nutrient dynamics: modelling blooming phenomenon. In Sustaining our Future: understanding and living with uncertainty, The 19th International Congress on Modelling and Simulation (MODSIM2011). Modelling and Simulation Society of Australia and New Zealand. 3698, 2011.

33. TUBAY J.M., ITO H., UEHARA T., KAKISHIMA S., MORITA S., TOGASHI T., TAINAKA K., NIRAULA M.P., CASARETO B.E., SUZUKI Y., YOSHIMURA J. The paradox of enrichment in phytoplankton by induced competitive interactions. Scientific Reports. 3 (3), 2835, 2013.

34. SUN G.W., CUI Q.W., SONG B. A new mathematical model of interspecific competition - an expansion of the classical Lotka-Volterra competition equations. Ecological modelling. 58, 273, 1991.

35. WANG B., SHEN Q. Effects of ammonium on the root architecture and nitrate uptake kinetics of two typical lettuce genotypes grown in hydroponic systems. Journal of plant nutrition. 35 (10), 1497, 2012.

36. LEMLEY D.A., SNOW G.C., HUMAN L.R.D. The decomposition of estuarine macrophytes under different temperature regimes. Water SA. 40 (1), 117, 2014.

37. HUMAN L.R., SNOW G.C., ADAMS J.B., BATE G.C., YANG S.C. The role of submerged macrophytes and macroalgae in nutrient cycling: A budget approach. Estuarine, Coastal and Shelf Science. 154, 169, 2015.

38. LENZI M., GENNARO P., MERCATALI I., PERSIA E., SOLARI D., PORRELLO S. Physico-chemical and nutrient variable stratifications in the water column and in macroalgal thalli as a result of high biomass mats in a non-tidal shallow-water lagoon. Marine pollution bulletin. 75 (1), 98, 2013.

39. NOWAK H., HARVEY T.H., LIU H.P., MCKAY R.M., ZIPPI P.A., CAMPBELL D.H., SERVAIS T. Filamentous eukaryotic algae with a possible cladophoralean affinity from the Middle Ordovician Winneshiek Lagerstätte in Iowa, USA. Geobios. 50 (4), 303, 2017.
40. MARTÍNEZ B., PATO L.S., RICO J.M. Nutrient uptake and growth responses of three intertidal macroalgae with perennial, opportunistic and summer-annual strategies. Aquatic botany. 96 (1), 14, 2012.

41. PIETRO K.C., CHIMNEY M.J., STEINMAN A.D. Phosphorus removal by the Ceratophyllum /periphyton complex in a south Florida (USA) freshwater marsh. Ecological Engineering. 27 (4), 290, 2006.

42. SONG M., LI M., LIU J. Uptake Characteristics and Kinetics of Inorganic and Organic Phosphorus by Ceratophyllum demersum. Water, Air, \& Soil Pollution. 228 (11), 407, 2017.

43. TANG Y., HARPENSLAGER S.F., VAN KEMPEN M.M., VERBAARSCHOT E.J., LOEFFEN L.M., ROELOFS J.G., LAMERS L.P. Aquatic macrophytes can be used for wastewater polishing but not for purification in constructed wetlands. Biogeosciences. 14 (4), 755, 2017.

44. DAI Y., WU J., MA X., ZHONG F., CUI N., CHENG S. Increasing phytoplankton-available phosphorus and inhibition of macrophyte on phytoplankton bloom. Science of the Total Environment. 579, 871, 2017.

45. KADLEC R.H., KNIGHT R.L. Treatment Wetlands. Lewis Publisher, Boca Raton, FL, USA, 893, 1996.

46. GÉRARD J., BRION N., TRIEST L. Effect of water column phosphorus reduction on competitive outcome and traits of Ludwigia grandiflora and L. peploides, invasive species in Europe. Aquatic Invasions. 9 (2), 157, 2014.

47. XIE D., YU D., YOU W. H., WANG L.G. Algae mediate submerged macrophyte response to nutrient and dissolved inorganic carbon loading: A mesocosm study on different species. Chemosphere. 93 (7), 1301, 2013.

48. DUAN B., DONG T., ZHANG X., ZHANG Y., CHEN J. Ecophysiological responses of two dominant subalpine tree species Betula albo-sinensis and Abies faxoniana to intraand interspecific competition under elevated temperature. Forest ecology and management. 323, 20, 2014.

49. BORNETTE G., PUIJALON S. Response of aquatic plants to abiotic factors: a review. Aquatic Sciences. 73, 1, 2011.

50. IRFANULLAH H.M., MOSS B. Allelopathy of filamentous green algae. Hydrobiologia. 543, 169, 2005.

51. KUMAR M., KUMARI P., REDDY C.R.K., JHA, B. Salinity and desiccation induced oxidative stress acclimation in seaweeds. Sea Plants. 71, 91, 2014. 